\title{
World Journal of Child access prevention legislative
Pediatric Surgery language and pediatric firearm injury rates
}

\author{
Bradford James (D) ," Bertha Ben Khallouq,, ${ }^{1,2}$ Hubert Swana ${ }^{3}$
}

To cite: James B, Khallouq BB, Swana $\mathrm{H}$. Child access prevention legislative language and pediatric firearm injury rates. World JnI Ped Surgery 2021;4:e000223. doi:10.1136/wjps-2020-000223

Received 18 0ctober 2020 Accepted 2 August 202

\section{Check for updates}

\section{(c) Author(s) (or their}

employer(s)) 2021. Re-use permitted under CC BY-NC. No commercial re-use. See rights and permissions. Published by BMJ.

${ }^{1}$ University of Central Florida College of Medicine, Orlando, Florida, USA

${ }^{2}$ Pediatric Diagnostic Lab, Arnold Palmer Hospital for Children, Orlando, Florida, USA

${ }^{3}$ Pediatric Urology, Arnold Palmer Hospital for Children, Orlando, Florida, USA

Correspondence to Bradford James; bradjames75@ knights.ucf.edu

\section{ABSTRACT}

Backgroud Firearm injuries are a significant public health problem facing young people in the USA. In 2015, a total of 16878 people under 19 years old were injured or killed by firearms. To reduce firearm injuries, 29 states and Washington, DC have enacted child access prevention (CAP) legislation. CAP legislation is intended to reduce the likelihood of a minor obtaining a weapon and subsequent injury or death. This study evaluates the impact of CAP legislation based on language of the legislation, specifically it evaluates a relationship of the legal threshold of liability and the number of firearm injuries per capita of minors. Methods Data were collected from the Web-based Injury Statistics Query and Reporting System for patients less than 19 years of age who presented to emergency departments with firearm injuries in 2016. The Giffords Law Center classification was used to group states into three categories (strong/weak/no CAP) based on CAP language. Differences of firearm-related injury rates per capita were assessed.

Results When controlling for population, states with CAP legislation had a $22 \%$ decrease in firearm injuries per capita compared with states without CAP Iegislation. States with 'strong' CAP legislation had a $41 \%$ decrease in firearm injuries per capita compared with states with 'weak' or no CAP legislation when controlling for population.

Conclusions States with 'strong' CAP legislation had lower pediatric firearm injury rates per capita, but more complete data and further studies are needed to evaluate this relationship as well as other factors that may impact firearm injury rates.

\section{INTRODUCTION}

Firearm-related incidents are a major cause of preventable injury and death for young people in the USA. In 2015 alone, 16,878 Americans under 19 years of age were either killed or injured with a gun. ${ }^{1}$ Firearms are the leading mechanism of suicide in the USA for the general population and the second leading mechanism of suicidal death for 10-24 year-olds. ${ }^{2}$ Restricting access to deadly weapons stored in the home has been shown to reduce suicide rates, ${ }^{34}$ and with $65 \%$ of US high school seniors in 2015 reporting to have at least one gun in their household the
Summary box

What is known?

- Firearms are a major preventable cause of injury and death for young people in the USA.

- Twenty-nine states and Washington, DC have forms of child access prevention (CAP) legislation.

- As a whole, states with CAP legislation have fewe firearm injuries.

What are the new findings?

- CAP legislation is able to be stratified based on legal language.

- The language that is used in CAP legislation may have real-world impacts on its effectiveness.

- Data related to firearm research are sparse, making effective research a difficult task.

How might it impact on clinical practice in the future?

- Providing people with accurate information on both the impact that firearm violence has on communities as well as methods to combat that violence is important. Informing the public on the dearth of data on the subject is an important aspect to current firearm research in hopes for a future with more encompassing data.

need to ensure safe storage seems clear. ${ }^{5}$ Even a relatively modest improvement in firearm safe storage practices could significantly reduce both intentional and unintentional firearm-related injuries and deaths. ${ }^{6}$

Firearm legislation is politically contentious, and currently no federal child access prevention (CAP) legislation exists. Twentynine states and Washington, DC have implemented various forms of CAP legislation. The intent of CAP legislation is to limit firearm access to minors by imposing criminal liability on adults who do not properly secure firearms. CAP legislation varies widely among states. In fact, the Giffords Law Center has stratified these laws based on legislative language. ${ }^{7}$ For example, California and Massachusetts base adult criminal liability on negligent storage, if a child 'may' or 'is likely to' access a firearm, ${ }^{89}$ whereas states such as Utah and 
Georgia have more legal leniency. In these more lenient states, criminal liability occurs only if the parent or legal guardians intentionally provide a firearm to a minor with knowledge that the minor will use the firearm to commit a crime. ${ }^{1011}$ The variation in legislative language (ie, strength of the law) may result in differences in the intended outcome of reducing firearm injuries and death. Previous studies looking into the effectiveness of CAP legislation have generally studied the topic in absolute terms. For example, Cummings et $a l^{12}$ studied all safe storage laws and found that storage laws decreased unintentional shooting deaths for children under 15 years of age. Similarly, DeSimone $e t a l^{13}$ found CAP laws were associated with reductions in non-fatal gun injuries for children under age 18. A more nuanced approach that considers the variability in legislative language inherent to CAP legislation may reveal different trends.

This study evaluates the effect that legislative language, specifically the basis for criminal liability, has on pediatric firearm injury rates.

\section{MATERIALS AND METHODS \\ Design}

This is a secondary analysis of the Centers for Disease Control and Prevention's (CDC) Web-based Injury Statistics Query and Reporting System (WISQARS), ${ }^{1}$ and was exempt from review by the Institutional Review Board at our institution. The WISQARS is an online database that provides fatal and non-fatal injuries, violent death, and cost of injury data from other sources, such as the National Electronic Injury Surveillance System-All Injury Program and the National Vital Statistics System. The WISQARS informs the public of economic and public health implications associated with unintentional and violence-related injuries in the USA.

The WISQARS was launched in 2015, and data are available from 2000 to 2019. For the present study, data for all firearm-related injuries recorded in the USA for persons under age 19 in 2016 and included in WISQARS were included. Despite the fact that many states have different legal definitions of 'minor', under age 19 was chosen because all states except three have laws declaring that being over 18 years old is the age of majority. ${ }^{14}$ Data were accessed on 14 June 2018, and at the time of data extraction, injury data for 38 states and Washington, DC were available (table 1 ). The availability of data varies across the years, and the period of study (2016) was selected because it was the year with the least gaps of data.

\section{Study definitions}

The Giffords Law Center's legislative descriptions were used to stratify states by CAP legislative strength. ${ }^{7} \mathrm{Negli}$ gent and intentional/reckless are the two broad categories that establish the basis for criminal liability, whereas six subcategories differentiate states' legislation further. Negligent storage language includes (i) 'may or is likely to gain access', (ii) 'gain access to [a] firearm, regardless of whether the child uses the firearm or causes injury', and (iii) 'only if a child uses or carries that firearm', whereas intentional/reckless storage, stratified by firearm type, includes (iv) 'all firearms', (v) 'all loaded firearms', and (vi) 'all handguns'. Category i (Child 'may or is likely to gain access' to a firearm) indicates the strongest CAP legislation, and category vi (all handguns) are the most lenient laws. States that have not adopted CAP legislation are considered in a separate category, as no CAP states (vii) (table 1). Accordingly, states that have adopted stricter laws (ie, negligent) are referenced here as 'strong' (categories i, ii, and iii). In contrast, states that have adopted more lenient laws (ie, intentional/reckless) are referenced here as 'weak' (categories iv, v and vi). Herewith references are 'strong' and 'weak' only.

\section{Data management}

In 2016, $27(54 \%)$ of US states and Washington, DC had adopted CAP legislation. Fifteen $(29.4 \%)$ states had adopted strong CAP legislation, $13(25.5 \%)$ states had adopted weak CAP legislation and $23(45.1 \%)$ states had not adopted any CAP legislation.

Among states that had adopted CAP legislation, injury data were available for 22/28 (79\%) states, and among states that had not adopted CAP legislation, data were available for $17 / 23$ states $(74 \%)$. Eleven states (Connecticut, Delaware, Hawaii, Maine, New Hampshire, Nebraska, North Dakota, Rhode Island, Vermont, West Virginia, and Wyoming) and the District of Columbia were missing injury data, and thus were omitted from analyses. Accordingly, this study includes data of 39 US states from 2016 (table 1).

\section{Statistical analyses}

State injury data are reported descriptively as counts and rates per 100,000 population. To answer our primary objective, three negative binomial regressions (NBR) were conducted to compare the number of firearm injuries based on the CAP legislation type. NBR is used for overdispersed count data, where interdependence cannot be assumed (in this study: mean $=51.79$; variance $=1559.85$ ), and NBR is particularly useful when analyzing crime data $^{15}$ because crime incidents are distributed as rare events that do not typically meet the assumptions of ordinal least squares regressions. ${ }^{16}{ }^{17}$ Furthermore, to allow for the possibility that crime rates change based on population size, we used the natural logarithm of the population [ $\ln$ (population)] and assigned the effect of this variable a fixed coefficient of 1 . The use of $[\ln (\mathrm{popu}-$ lation)] converts the NBR to an analysis of rates of events per capita, rather than an analysis of counts of events and allows us to account for the size of the population while also acknowledging the greater precision of rates based on larger population and addressing the heterogeneity of error variance. ${ }^{16} 18$

Model 1 included a two-level independent variable, CAP legislation (reference) and no CAP legislation as predictors of firearm injury rates per capita. In model 2, 
Table 1 Classification of CAP legislation and pediatric injuries in the USA in 2016

\begin{tabular}{|c|c|c|c|c|c|}
\hline \multicolumn{2}{|l|}{ Giffords classification $†$} & \multirow{2}{*}{$\begin{array}{l}\text { State } \\
\text { California }\end{array}$} & \multirow{2}{*}{$\begin{array}{l}\text { Population (<19 y) } \\
9644812.00\end{array}$} & \multirow{2}{*}{$\begin{array}{l}\text { Injuries (n) } \\
175\end{array}$} & \multirow{2}{*}{$\begin{array}{l}\text { Injuries per } \mathbf{1 0 0 0 0 0} \\
1.81\end{array}$} \\
\hline $\begin{array}{l}\text { Negligent storage } \\
\text { (strong) }\end{array}$ & $\begin{array}{l}\text { May or is likely to gain access } \\
\text { (i) }\end{array}$ & & & & \\
\hline & & District of Columbia* & & & \\
\hline & & Massachusetts & 1483717.00 & 13 & 0.88 \\
\hline & & Minnesota & 1353296.00 & 30 & 2.22 \\
\hline & 'Gain access to [a] firearm, & Hawaii* & & & \\
\hline & causes injury' (ii) & New Jersey & 2110496.00 & 20 & 0.95 \\
\hline & & Texas & 7598212.00 & 173 & 2.28 \\
\hline & Only if a child uses or carries & Connecticut $^{\star}$ & & & \\
\hline & & Florida & 4334562.00 & 117 & 2.7 \\
\hline & & North Carolina & 2423278.00 & 62 & 2.56 \\
\hline & & Rhode Island* & & & \\
\hline \multirow{7}{*}{$\begin{array}{l}\text { Intentional or reckless } \\
\text { storage (weak) }\end{array}$} & All firearms (iv) & Indiana & 1665277.00 & 67 & 4.02 \\
\hline & & Missouri & 1466996.00 & 65 & 4.43 \\
\hline & & Nevada & 702416.00 & 22 & 3.13 \\
\hline & & Oklahoma & 1010825.00 & 36 & 3.56 \\
\hline & & Utah & 956627.00 & 34 & 3.55 \\
\hline & All loaded firearms (v) & Delaware* $^{*}$ & & & \\
\hline & & Wisconsin & 1370170.00 & 32 & 2.34 \\
\hline \multirow[t]{18}{*}{ No CAP legislation (vii) } & & Alabama & 1163902.00 & 55 & 4.73 \\
\hline & & Alaska & 195597.00 & 17 & 8.69 \\
\hline & & Arizona & 1715007.00 & 46 & 2.68 \\
\hline & & Arkansas & 745099.00 & 30 & 4.03 \\
\hline & & Idaho & 455260.00 & 13 & 2.86 \\
\hline & & Kansas & 757642.00 & 16 & 2.11 \\
\hline & & Louisiana & 1173986.00 & 71 & 6.05 \\
\hline & & Maine* & & & \\
\hline & & Michigan & 2343247.00 & 64 & 2.73 \\
\hline & & Montana & 238727.00 & 20 & 8.38 \\
\hline & & Nebraska* & & & \\
\hline & & New Mexico & 523266.00 & 22 & 4.2 \\
\hline & & New York & 4465391.00 & 50 & 1.12 \\
\hline & & Ohio & 2779110.00 & 83 & 2.99 \\
\hline & & North Dakota* & & & \\
\hline & & Oregon & 911755.00 & 20 & 2.19 \\
\hline & & Pennsylvania & 2859747.00 & 72 & 2.52 \\
\hline & & South Carolina & 1154597.00 & 47 & 4.07 \\
\hline
\end{tabular}


Table 1 Continued

\begin{tabular}{llccc}
\hline Giffords classification† & State & Population (<19 y) & Injuries (n) & Injuries per 100 000 \\
\hline & South Dakota & 222358.00 & 10 & 4.5 \\
& Vermont* & & \\
& Washington & 1804560.00 & 49 & 2.72 \\
& West Virginia* & & \\
& Wyoming* & & \\
\hline
\end{tabular}

*Data unavailable via WISQARS at time of query.

†Giffords Law Center. ${ }^{7}$

CAP, child access prevention; WISQARS, Web-based Injury Statistics Query and Reporting System.

we used a three-level variable that included strong CAP legislation, weak CAP legislation, and no CAP legislation (reference) as predictors of firearm injury rates per capita. The final model (model 3) included strong CAP legislation (reference) and 'other states' (inclusive of all states with weak and no CAP legislation) as predictors of firearm injury rates per capita. Incidence rate ratio (IRR) is reported with $95 \%$ confident interval (CI). The IRR represents the change in the dependent variable in terms of a percent increase or decrease, which is determined by the value of the IRR as above or below 1 . A value of $\mathrm{p}<0.05$ was used to determine statistical significance. Analyses were conducted using Stata (StataCorp. 2019. Stata Statistical Software: Release 16.1).

\section{RESULTS}

\section{CAP legislation}

As previously mentioned, at the time of the study, data for 39 states were available for analyses: 22 states with CAP legislation and 17 without.

Overall, firearm injury rates ranged from 0.88 to 8.69 per 100000 minors in Massachusetts and Alaska, respectively. Among states with CAP legislation, Missouri had the largest number of injuries at 4.43 per 100000 minors, whereas Massachusetts had the lowest injury rate at 0.88 per 100000 .

A closer look at injury rates, based on the strength of the CAP legislations, reveals that among states with 'strong' CAP legislation, Illinois had the highest injury rate per 100000 and Massachusetts had the lowest injury rate (3.46 and 0.88 per 100000 , respectively).

Switching focus to states with 'weak' CAP legislation, Missouri had the highest rate of injury at 4.43 per 100000 and Wisconsin the lowest at 2.34 per 100000 .

Alaska had the highest injury rates among states with no CAP legislation at 8.96 per 100000 minors (also the highest in the country), and New York the lowest at 1.12 per 100000 (table 1).

\section{Differences in firearm injury rates}

CAP states versus no CAP states

Injury rates are lower in states that adopted CAP legislation when compared with states that did not adopt CAP legislation (IRR $=0.78,95 \%$ CI 0.60 to 1.03 ). The rates of firearm injuries per capita in states with CAP legislation are 22\% lower than those in states with no CAP legislation, although these differences were not statistically significant $(\mathrm{p}=0.08)$.

\section{Strong CAP, weak CAP and no CAP legislation states}

Injury rates per capita are significantly lower in states that adopted strong CAP legislation, when compared with states that did not adopt CAP legislation (IRR=0.59, 95\% CI 0.44 to $0.79, \mathrm{p}<0.001$ ). Adoption of strong CAP legislation decreased injury rates per capita by approximately $41 \%$. When looking at states that adopted weak CAP legislation and states that did not adopt CAP legislation, we also note $2 \%$ lower injury rates, although the differences were not statistically significant (IRR $=0.98,95 \%$ CI 0.74 to $1.30, \mathrm{p}=0.90$ ).

\section{Strong CAP states versus other states}

Injury rates per capita are significantly lower in states that adopted strong CAP legislation, when compared with other states, inclusive of states with weak and no CAP legislation (IRR $=0.59,95 \%$ CI 0.46 to $0.77, \mathrm{p}<0.001)$. This suggests that rates of firearm injuries are $41 \%$ lower for states with strong CAP legislation than the 'other states'.

\section{DISCUSSION}

Children and adolescents in the USA are at a greater risk of death from firearm-related injury than cancer, congenital abnormalities, pneumonia, or the influenza. ${ }^{1}$ In 2016, 43\% (1101/2506) of suicides reported among young people were by firearms. Similarly, of the 2441 who were killed in $2016,75 \%$ were by firearms. ${ }^{1}$ Due in part to unsafe storage, firearm thefts surpass 350000 per year. $^{19}$ The American Academy of Pediatrics recommends that parents store firearms, unloaded, in a separate location than ammunition and under lock and $\mathrm{key}^{20}$; yet, estimates suggest that these recommendations are followed by a small proportion of gun-owning parents, estimates ranging from $30 \%$ to $46 \%$. $^{21} 22$

As a method of suicide reduction, previous research offers some evidence on CAP legislations' effectiveness. ${ }^{23}$ This conclusion was drawn mainly from a study done by Webster $e t a l^{24}$ where they found a statistically significant decrease in suicides among children aged 14-17 in states that had CAP legislation. Similarly, Cummings et $a l^{12}$ reported a decline in youth suicides after CAP 
implementation. Taken together, these studies suggest that adoption of CAP legislation may reduce firearm suicide rates, but neither of these studies accounted for the language of CAP legislation.

CAP legislation may also reduce the rates of firearmrelated injuries, including death. ${ }^{23}$ Using hospital admission data, DeSimone $e t a l^{13}$ found a statistically significant reduction in all non-fatal gun injuries in states with CAP legislation. As another example, Schell et $a t^{25}$ estimated that if CAP legislations were implemented in all US states, within 6 years, there would be over 2500 fewer firearm-related deaths nationally than if no states had CAP laws. ${ }^{14}$ Similarly, Webster and Starnes ${ }^{26}$ stratified legislation by comparing states with felony CAP laws to misdemeanors and found statistically significant reduction in unintentional firearm deaths for children under age 14 in felony states, but the difference was not significant in misdemeanor states. The investigation by Webster and Starnes ${ }^{26}$ is significant because it illustrated the importance of legislative stringency. Our results are consistent with Webster et al despite the different legal stratification criteria. Azad et al found that states with CAP legislation based on negligence had a $13 \%$ relative reduction in firearm fatalities, for children aged 0-14. They also found that from 1991 to 2016, approximately 3929 deaths were attributed to states not passing the most stringent form of CAP legislation. ${ }^{27}$

Our study has taken a nuanced approach to the analyses of CAP legislation. Results suggest a significant lower count of firearm injuries among states that have strong CAP legislation compared with states without CAP legislation, and the evidence presented highlights the importance of legal language in CAP legislations. Model 1 suggests that rates of firearm injuries in states with CAP legislation are $1 \%$ lower than states with no CAP legislation. Our data also suggest (model 2) that rates of firearm injuries per capita in states with strong or weak CAP legislation are lower than those in states with no CAP legislation. These findings mirror the previous work by Hamilton $e t a t^{28}$ and DeSimone and colleagues. ${ }^{13}$ Both of these studies found a decrease in pediatric injury rates in states that had implemented CAP legislation, and concluded that CAP legislation might have an impact on pediatric firearm-related injury rates. The present study contributes to this literature by presenting additional evidence that strongly crafted CAP legislation is associated with lower pediatric firearm-related injury counts. Collectively, this evidence could guide further legislation at the state and federal levels.

There are several limitations to our study. The WISQARS data set is evolving, and data from all 50 states were not available. As the data set matures and as additional data become available, a more detailed and representative analysis will be possible, including an analysis of changes across time. Our results demonstrate an association between strong CAP legislation and lower pediatric injury rates, but our results do not establish a causal relationship. Furthermore, we do not account for other social factors that are known to influence crime and injury rates, such as state poverty levels, crime indices, neighborhood racial marginalization, policing and structural racism. Some of these state-level data are available in the US Social Explorer via census tracks; however, our data are based on state level and we cannot accurately pinpoint firearm injury location to match with census track data. Therefore, rather than enhancing our analyses, the use of census-derived data in combination with our state-level data would not have been appropriate.

Legislative measures are designed to influence human behavior, including implementation by law enforcement. Our study, however, did not evaluate CAP enforcement and it does not measure or account for enforcement irregularities. Some states that enact strong CAP legislation generally have a stronger firearm legislation. The individual and cumulative impacts of other types of firearm laws need to be evaluated as well.

Some of the limitations noted have been reported by other researchers. ${ }^{13} 2628$ Decreases in research funding and legislation, such as the Dickey Amendment, a provision put in place in a 1996 federal spending omnibus, ${ }^{29}$ make studying US firearm-related morbidity and mortality difficult. The initial intent of the Dickey Amendment was to prevent the use of federal funding to advocate or promote gun control policies through the CDC, but the Amendment has resulted in the limitation of federal funding of virtually all firearm-related research through the CDC. ${ }^{30}$ Prior to 2020, firearm-related research received $\$ 2$ million per year in federal funding, as opposed to cancer research, which received $\$ 4$ billion per year. This amounts to only $\$ 2.70$ per year of life loss and to pennies per injury. ${ }^{31}$ In March 2018, a memo from then Health and Human Services Secretary, Alex Azar, accompanied the 2018 spending bill. Although the Dickey Amendment was still present in the spending bill, 'the CDC has the authority to conduct research on the causes of gun violence'. ${ }^{32}$ The authors hope that future studies of firearm-related research can receive increased federal attention and support.

The future holds promise. In December 2019, for the first time in over 20 years, the federal government allocated $\$ 25$ million split evenly between the CDC and the National Institutes of Health for gun violence research. ${ }^{33}$ Support from medical professional associations has also gained visibility. The American Academy of Pediatrics ${ }^{34}$ and the Pediatric Trauma Society, ${ }^{35}$ for example, support the implementation of CAP legislation, and the Society of Adolescent Medicine supports increased research into CAP legislation. ${ }^{36}$ CAP legislation, however, is only one piece of the public health concern to reduce harm. Other measures, such as universal background checks, assault weapon bans, high-capacity magazine restrictions, and minimum purchase age policies, also can be used. These restrictions and policies also should be diligently studied with careful attention to language and legislative strength. As has been shown, language matters, and it is a relevant and influential factor to consider 
in research. Legislation alone will not be sufficient in reducing firearm injuries and death. The American Pediatric Surgical Association has recommended a multidimensional approach, and points to American success in reducing motor vehicle fatalities using a combination of 'prevention, design, policy behavior and trauma care'.

CAP legislation is not a cure-all for the problems Americans face regarding gun injuries, but as our work and previous work have shown, CAP legislation can be a piece of the puzzle. By limiting the access that minors have to guns, strong CAP legislation could decrease firearm injuries of minors.

In conclusion, data show that states that have legal liability for safe gun storage based on negligence report lower firearm injury rates for minors than states with no CAP legislation or those with liability relying on intentional or reckless storage. Additional data and studies are needed to assess the effectiveness and implementation of CAP legislation.

\section{Twitter Bradford James @Brad_LW_James}

Contributors BJ contributed to conceptualisation, data curation, methodology, resources, validation, investigation, project administration, writing-original draft, writing-review and editing. BBK contributed to conceptualisation, data curation, methodology, resources, validation, formal analysis, software, investigation, project administration, writing-original draft; writing-review and editing. HS contributed to supervision, investigation, project administration, writing-original draft; writing-review and editing. All authors contributed to the article and approved the submitted version.

Funding The authors have not declared a specific grant for this research from any funding agency in the public, commercial or not-for-profit sectors.

Competing interests None declared.

Patient consent for publication Not required.

Ethics approval Institutional review board exemption was obtained through University of Central Florida because the manuscript was written with use of public deidentified data.

Provenance and peer review Not commissioned; externally peer reviewed.

Data availability statement Data are available in a public, open access repository. The data that support the findings of this study are openly available in the Web-based Injury Statistics Query and Reporting System (WISQARS) at https:// www.cdc.gov/injury/wisqars/index.html.

Open access This is an open access article distributed in accordance with the Creative Commons Attribution Non Commercial (CC BY-NC 4.0) license, which permits others to distribute, remix, adapt, build upon this work non-commercially, and license their derivative works on different terms, provided the original work is properly cited, appropriate credit is given, any changes made indicated, and the use is non-commercial. See: http://creativecommons.org/licenses/by-nc/4.0/.

ORCID iD

Bradford James http://orcid.org/0000-0003-4975-7218

\section{REFERENCES}

1 Centers for Disease Control and Prevention. Web-Based injury statistics query and reporting system (WISQRS), 2015. Available: https://www. cdc.gov/injury/wisqars/index.html [Accessed 27 May 2019].

2 Sullivan EM, Annest JL, Simon TR, et al. Suicide trends among persons aged 10-24 years--United States, 1994-2012. MMWR Morb Mortal Wkly Rep 2015;64:201-5 https://www.cdc.gov/mmwr/ preview/mmwrhtml/mm6408a1.htm

3 Rodríguez Andrés A, Hempstead K. Gun control and suicide: the impact of state firearm regulations in the United States, 1995-2004. Health Policy 2011;101:95-103.

4 Kposowa A, Hamilton D, Wang K. Impact of firearm availability and gun regulation on state suicide rates. Suicide Life Threat Behav 2016;46:678-96.
5 Coker AL, Bush HM, Follingstad DR, et al. Frequency of guns in the households of high school seniors. J Sch Health 2017;87:153-8.

6 Monuteaux MC, Azrael D, Miller M. Association of increased safe household firearm storage with firearm suicide and unintentional death among US youths. JAMA Pediatr 2019;173:657-7.

7 Giffords Law Center. Child access prevention, 2018. Available: https://lawcenter.giffords.org/gun-laws/policy-areas/child-consumersafety/child-access-prevention/ [Accessed 1 July 2019].

8 Cal. Penal code $\S \S 25000-25225$; CAL. CIV. code $\S 1714.3$.

9 Mass. gen. laws CH. 140, § 131L.

10 Ga. code Ann. § 16-11-101.1.

11 Utah code ANN. § 76-10-509.6.

12 Cummings P, Grossman DC, Rivara FP, et al. State gun safe storage laws and child mortality due to firearms. JAMA 1997;278:1084-6.

13 DeSimone J, Markowitz S, Xu J. Child access prevention laws and nonfatal gun injuries. South Econ $J$ 2013;80:5-25.

14 USLegal. Age of majority, 2019. Available: https://minors.uslegal. com/age-of-majority/ [Accessed 1 Sep 2020].

15 Macdonald JM, Lattimore PK. Handbook of quantitative criminology. Vol 1. New York: Springer New York, 2010.

16 Osgood DW. Poisson-based regression analysis of aggregate crime rates. J Quant Criminol 2000;16:21-43.

17 Maxfield MG, Babbie ER. Research methods for criminal justice and criminology. 7th Ed. Boston, MA: Cengage Learning, 2017.

18 Long JS, Freese J. Regression models for categorical depending variables using Stata. 2nd Ed. College Station, TX: Stata Press, 2006

19 Freskos B. Missing pieces: gun theft from legal owners is on the rise, quietly fueling violent crime across America. The trace, 2017. Available: https://www.thetrace.org/features/stolen-guns-violentcrime-america/ [Accessed 29 Jun 2019].

20 Dowd MD, Sege RD, et al, Council on Injury, Violence, and Poison Prevention Executive Committee. Firearm-related injuries affecting the pediatric population. Pediatrics 2012;130:e1416-23.

21 Azrael D, Cohen J, Salhi C, et al. Firearm storage in Gun-Owning households with children: results of a 2015 national survey. J Urban Health 2018;95:295-304.

22 Crifasi CK, Doucette ML, McGinty EE, et al. Storage practices of US gun owners in 2016. Am J Public Health 2018;108:532-7.

23 Morral A, Ramchand R, Smart R. The science of gun policy: a critical synthesis of research evidence on the effects of gun policies in the United States. Vol 1. Santa Monica, CA: RAND Corporation, 2018.

24 Webster DW, Vernick JS, Zeoli AM, et al. Association between youth-focused firearm laws and youth suicides. JAMA 2004;292:594-601.

25 Schell TL, Cefalu M, Griffin BA, et al. Changes in firearm mortality following the implementation of state laws regulating firearm access and use. Proc Natl Acad Sci U S A 2020;117:14906-10.

26 Webster DW, Starnes M. Reexamining the association between child access prevention gun laws and unintentional shooting deaths of children. Pediatrics 2000;106:1466-9.

27 Azad HA, Monuteaux MC, Rees CA, et al. Child access prevention firearm laws and firearm fatalities among children aged 0 to 14 years, 1991-2016. JAMA Pediatr 2020;174:463.

28 Hamilton EC, Miller CC, Cox CS, et al. Variability of child access prevention laws and pediatric firearm injuries. J Trauma Acute Care Surg 2018;84:613-9.

29 104th United States Congress. Public Law 104-208. 1996;30.

30 Kellermann AL, Rivara FP. Silencing the science on gun research. JAMA 2013;309:549-50.

31 Stark DE, Shah $\mathrm{NH}$. Funding and publication of research on gun violence and other leading causes of death. JAMA 2017;317:84-5.

32 H.R.7614. Departments of Labor, Health and Human Services, and Education, and Related Agencies Appropriations Act. Washington, DC: House Appropriations Committee, 2018.

33 Subbaraman N. United States to fund gun-violence research after 20-year freeze. Nature 2020;577:12.

34 American Academy of Pediatrics. State advocacy focus. American Academy of pediatrics. Vol 1. Itasca, IL: American Academy of Pediatrics, 2018.

35 Pediatric Trauma Society. Pts position Satement on gun violence. Available: http://www.pediatrictraumasociety.org/news/positionstatements/Gun-Violence.cgi [Accessed 29 Jun 2019].

36 Duke N, Resnick MD, Borowsky IW. Adolescent firearm violence: position paper of the Society for adolescent medicine. Journal of Adolescent Health 2005;37:171-4.

37 Petty JK, Henry MCW, Nance ML, et al. Firearm injuries and children: position statement of the American pediatric surgical association. $J$ Pediatr Surg 2019;54:1269-76. 